\title{
Spanning the Boundary: Measuring the Realized and Lifecycle Impact of Distinct Boundary Spanning Activities on Project Success and Completion
}

\author{
Wietske Van Osch \\ Michigan State University \\ vanosch@msu.edu
}

\author{
Charles W. Steinfield \\ Michigan State University \\ steinfie@msu.edu
}

\author{
Yanjie Zhao \\ Michigan State University \\ zhaoyanj@msu.edu
}

\begin{abstract}
For work teams to be effective, maintaining communication ties with other individuals and teams elsewhere in the organization-an activity typically referred to as team boundary spanning-is necessary for obtaining resources critical to project success. Within the literature on boundary spanning, the positive relationship between a team's boundaryspanning activities and their performance has been validated repeatedly, but primarily through the use of self-reports from managers and team members. Thus, neither objective data exists to support these claims nor a longitudinal understanding of how various boundary-spanning activities may play different roles at various stages of project work. Similarly, with the proliferating use of enterprise social media (ESM) technologies in organizations, the empirical link between the increased visibility of communication ties in ESM and more effective boundary spanning has been largely assumed, but has received only limited empirical validation. In this study, drawing on log and content data from 169 projects in an ESM of a large multi-national corporation, we aim to objectively assess the effect of boundary spanning on project success as well as provide a qualitative path model of the evolution of boundary-spanning activities throughout the lifecycle of a project through a comparison of successful versus unsuccessful projects. Implications for theory and practice are discussed.
\end{abstract}

\section{Introduction}

Team boundary spanning, the maintaining of communication ties with other teams inside the organization for obtaining access to resources, has long been considered a critical antecedent to project success and team performance [c..f, 1-8]. However, one characteristic of all boundary-spanning studies until recently was their reliance on survey or interview data for the empirical validation of the link between boundary spanning and team performance; usually based on responses from team members and managers.

Biases in retrospective self-reports have been documented in the management sciences for decades $[9,10]$. Similarly, Marrone [11:936] in a recent review of the boundary-spanning literature, highlighted the overreliance on small-scale qualitative methods and surveys (both scale-based and social network surveys) in this field of study. Indeed, we identified only two studies that used some unobtrusive log data for performance metrics [1,2], whereas boundary-spanning activities have been assessed through self-reports only. These measurement issues seem largely a function of the fact that, until recently, our ability to capture a team's actual boundary-spanning activities as well as unobtrusive performance data was relatively impossible.

With the proliferating use of ESM technologies in organizational settings, we now have the ability to analyze the digital traces of teams' and team members' boundary-spanning activities as well as some basic project success metrics. Furthermore, given the improved visibility of communication ties as a result of ESM, the opportunity for boundary-spanning activities in the context of ESM are unprecedented.

In collaboration with a multi-national, Fortune 500 corporation in the Midwestern United States, we set out to explore the actual link between realized as opposed to self-reported boundary-spanning activities and an unobtrusive project outcome measure. Using content and log data from 169 project teams, we aim to answer three research questions.

First, we aim to understand the overall link between a team's enactment of distinct boundaryspanning activities, on the one hand, and their project success and timeliness of project completion, on the other hand. Thus, using behavioral data, we aim to answer the first question: What are the effects of the enactment of distinct team boundary-spanning activities on project success and timeliness of completion?

Second, although the earlier boundary-spanning literature has focused on the overall link between 
boundary-spanning activities and project success, the longitudinal evolution of boundary-spanning activities throughout the lifecycle of project teams has received no attention to date in the absence of longitudinal data. Using the digital traces of projects from the ESM, we use a qualitative path model to map the actual occurrence of boundary spanning activities as a project unfolds overtime, to answer the second question: What is the evolution of team boundary spanning activities throughout the project lifecycle?

Third, to statistically validate whether the impact of distinct boundary-spanning activities is significantly different at various stages of the project lifecycle, we aim to answer our final research question: What are the effects of the occurrence of each type of boundary spanning activity on the successful completion of each of the stages in a project lifecycle.

Answering these three research questions offers a number of contributions to research and practice. First, to the boundary-spanning literature, we provide a behavioral assessment of the empirical link between realized boundary spanning and actual project success; a link that has hitherto largely been established using self-reported data on boundary spanning and performance. Second, we contribute a longitudinal perspective of the significance of distinct boundaryspanning activities at various stages of the project lifecycle. Offering this longitudinal aspect allows to obtain a better understanding of not only whether a link between boundary-spanning and project success exists, but the underlying mechanisms of this link and specifically the particular boundary-spanning activities that are most critical at different stages of the project lifecycle. Thus, the longitudinal insights generated by this study offer significant insights for theory and practice in regards to our understanding of how boundary spanning leads to project success-i.e., the specific sequencing of boundary-spanning activitiesand how boundary spanning can be improved-i.e., by influencing the specific sequencing of activities. Third, to the ESM literature, we contribute insights into whether the use of ESM for boundary-spanning impacts the success of projects; thereby offering largescale empirical insights into the usefulness of ESM technologies for organizational teams to a body of literature that has relied heavily on qualitative and anecdotal evidence. Finally, with respect to practice, we provide managers with empirical insights into the value of investments in ESM technologies, specifically in the context of boundary spanning and project work.

The remainder of this paper is organized as follows. We first review the literature on team boundary spanning as well as the link between boundary spanning and team performance. We further review literature on project and team lifecycles, to hypothesize the relative importance of distinct boundary-spanning activities at various project stages. Subsequently, we describe the case organization, data collection and measurement as well as the approach to data analyses and hypotheses testing. We then present our findings. Finally, we discuss next steps as well as important implications for research and practice.

\section{Theoretical Background}

\subsection{Team Boundary Spanning}

Team boundary spanning is concerned with the extent to which communication links work groups to external sources of information, either within or outside the organization [12]. Theoretical development in this area was pushed forward by Ancona and Caldwell [1,2] in order to understand the interactions team members engage in with other employees and teams in the organization to obtain the resources, knowledge, or legitimacy required to complete projects successfully.

More recently, the focus in the boundary-spanning literature has shifted to the concept of technological gatekeepers. This work differs from our use of the term boundary spanning as well as the early literature in two ways. First, much of this new work does not emphasize team-level boundary spanning inside the organization, but rather focuses on the absorption of knowledge and information residing outside the organization; hence, is closely akin to the concept of absorptive capacity [13]. Second, although the concept of the technological gatekeeper focuses on technology support for information search and filtering, it does not explicitly examine the role of social media and specifically ESM for changing patterns of internal or team-level boundary spanning.

Within the original team boundary-spanning literature, three distinct boundary-spanning activities have been conceptualized theoretically and validated empirically $[1,2]$, namely representation, coordination, and information search. In this section, we only define these three activities, whereas the next paragraph explains why all three activities are critical antecedents of project success. Representation involves the lobbying for the team up the hierarchy in order to create favorable impressions amongst senior managers, hence, is a largely vertical form of boundary spanning [1]. Coordination involves the facilitation of effective decision-making and design implementation through cross-boundary strategizing, planning, and evaluation with interdependent teams and people; hence it is a horizontal form of boundary spanning $[1,15]$. General information search involves the general scanning of the external team environment to gain access to 
relevant information, knowledge, and expertise about trends, opportunities and threats; hence, is also largely horizontal form of boundary spanning [1]. Target actors of information search activities are often loosely coupled with the focal team [11].

As opposed to public social media, ESM support private communication within organizations, including interactions between organizational members in teams or groups [16], thereby mitigating some of the risks of inadvertent release of proprietary information associated with public social media $[17,18]$. As such, ESM offers better support for team boundary spanning processes by avoiding security and confidentiality issues. This also implies that ESM restricts boundaryspanning exchanges to interactions between work groups and employees within the boundaries of the firm.

The proliferation of enterprise social media has the potential to enhance team boundary spanning by offering group members a relatively low effort vehicle for making work activities as well as common areas of interest visible to others in the organization, which can help improve users meta-knowledge of who knows what and whom and thus help locate and connect with relevant resources outside their local environment [1924]. Hence, the visibility affordance of ESM seems to make these novel platforms particularly useful for groups to enact these three boundary-spanning activities. For instance, an exchange between two coworkers on an ESM may also appear in the newsfeed of a third co-worker, who can now learn about important topics being discussed [25]. Similarly, through the articulation of one's social network and by tagging posts, documents, or images, colleagues not directly involved in the communication obtain useful information about what and whom someone knows, which can improve knowledge-seeking efforts [26].

\subsection{Project Success}

The boundary spanning literature has relied on a variety of team outcome measures to validate the positive effects of team boundary spanning. Table 1 provides an overview of the performance and success metrics used in prior boundary-spanning literature (adapted from [11]).

\begin{tabular}{|c|c|c|c|}
\hline Study & Method & Sample Size & $\begin{array}{c}\text { Performance/Succes } \\
\text { s Variable }\end{array}$ \\
\hline $\begin{array}{c}\text { Ancona \& } \\
\text { Caldwell } \\
(1992 \mathrm{a},\end{array}$ & $\begin{array}{c}\text { Interviews, } \\
\text { surveys, logs, } \\
\text { observation }\end{array}$ & $\begin{array}{c}45 \text { product } \\
\text { development } \\
\text { teams }\end{array}$ & $\begin{array}{c}\text { Team performance } \\
\text { (budget, efficiency, } \\
\text { operation, and } \\
\text { innovation); team } \\
\text { ratings of } \\
\text { performance }\end{array}$ \\
\hline Ancona & Interviews, & 5 consulting & Team performance \\
\hline
\end{tabular}

\begin{tabular}{|c|c|c|c|}
\hline $\begin{array}{c}\text { (1990) } \\
\text { surveys, logs, } \\
\text { observation }\end{array}$ & teams & \\
\hline $\begin{array}{c}\text { Edmonso } \\
\mathrm{n}(1999 / \\
2003)\end{array}$ & $\begin{array}{c}\text { Survey/ } \\
\text { Interviews, } \\
\text { observation }\end{array}$ & $\begin{array}{c}51 \text { work } \\
\text { teams; } 16 \\
\text { operating } \\
\text { rooms }\end{array}$ & $\begin{array}{c}\text { Team performance / } \\
\text { Team learning }\end{array}$ \\
\hline $\begin{array}{c}\text { DeChurch } \\
\text { \& Marks } \\
(2006)\end{array}$ & $\begin{array}{c}\text { Manipulation } \\
\text { observation, } \\
\text { surveys }\end{array}$ & $\begin{array}{c}\text { 64 multi- } \\
\text { team } \\
\text { systems } \\
\text { (MTS) }\end{array}$ & $\begin{array}{c}\text { Team and MTS } \\
\text { performance }\end{array}$ \\
\hline $\begin{array}{c}\text { Faraj \& } \\
\text { Yan } \\
(2009)\end{array}$ & Surveys & $\begin{array}{c}64 \text { software } \\
\text { development } \\
\text { teams }\end{array}$ & $\begin{array}{c}\text { Team performance } \\
\text { (goal achievement) }\end{array}$ \\
\hline $\begin{array}{c}\text { Gladstein } \\
(1984)\end{array}$ & $\begin{array}{c}\text { Surveys, } \\
\text { archival }\end{array}$ & $\begin{array}{c}100 \text { sales } \\
\text { teams }\end{array}$ & $\begin{array}{c}\text { Team effectiveness, } \\
\text { sale revenue }\end{array}$ \\
\hline $\begin{array}{c}\text { Marrone, } \\
\text { Tesluk \& } \\
\text { Carson } \\
(2007)\end{array}$ & Surveys & $\begin{array}{c}31 \mathrm{MBA} \\
\text { student } \\
\text { teams }\end{array}$ & $\begin{array}{c}\text { Team performance } \\
\text { (effectiveness) }\end{array}$ \\
\hline
\end{tabular}

Table 1. Summary of Performance Variables in Prior Team Boundary-Spanning Studies

In the previous section, we defined all three boundary-spanning activities. Here we outline their respective benefits for project teams and why all three activities are considered critical antecedents of project success.

First, representation is crucial for team performance as the creation of a favorable impression among senior management is a prerequisite for obtaining access to key resources (e.g., reputation, legitimization, higher-level commitment) and financial support needed for successful product development and project completion [1,2]. Representation further benefits management as it helps organizational leaders stay informed of team progress and supports higherlevel planning and resource allocation decisions, which in turn, can help the organization meet external client expectations (cf., [11]).

Second, coordination is crucial for team performance and project success as it involves the aligning, negotiating, and monitoring of the efforts of individuals - within and outside the team - in order to accomplish project goals (e.g., delivery deadlines). Hence, coordination is crucial for the efficiency, effectiveness, innovativeness, and flexibility of project goal delivery $[1,2,14,28]$. Coordination further benefits the organization at large by improving organization learning, operational efficiency, and the achievement of organizational goals [11].

Third, the information search process is crucial for team performance and project success as it enables teams to gain project-specific expertise and an understanding and shared awareness of trends, opportunities, and threats in the external environment [27]. Information search further benefits the 
organization at large by enhancing the likelihood of successful innovation [11].

These three types of team boundary spanning activities were previously validated using self-reported, retrospective measures of boundary spanning and project success $[1,2,14]$. Based on this review, we propose that:

H1: The enactment of boundary-spanning activities in ESM will have a positive effect on project success. Specifically:

Hla: The enactment of representation activities in ESM will have a positive effect on project success

$H 1 b$ : The enactment of coordination activities in ESM will have a positive effect on project success

H1c: The enactment of information search in ESM will have a positive effect on project success

\subsection{Project and Team Lifecycle}

Although the boundary-spanning literature has focused on the overall link between the enactment of the three boundary-spanning activities - representation, coordination, and information search-on team performance and project success, the project management literature generally considers projects to have various stages.

The most well-accepted project lifecycle model is that used by the Project Management Institute, which divides a project into four stages; namely initiating, planning, executing, and closing [29]. The initiating phase focuses on conceptualization through acquiring specifications as well as information about opportunities, trends, and threats in the environment [29]. The needs of this phase thus seem to be best supported through information search, that is, the general scanning of the external team environment to gain access to relevant information, knowledge, and expertise $[11,14]$.

The planning stage is largely focused on obtaining resources the group needs in order to complete the project as well as the development of the envisioned schedule and budget [29]. As such, the needs of this phase seem to be best supported through representational activities-lobbying up the corporate hierarchy to obtain access to resources-and coordination activities - the synchronization of timelines and budgets $[11,14]$.

The executing stage is the phase during which most of the project work happens and this stage involves numerous planning, scheduling, conflict resolution, and negotiation activities [29]. Thus, the needs of the third project phase seem to be best supported by coordination activities, which involve synchronization efforts and negotiation acts between individuals belonging to different departments in the organization $[11,14]$.

Finally, the closing stage of the project involves finalization of project tasks, outcomes, and documentation [29]. Since the closing stage only occurs when a project is successful, we anticipate that this stage will likely be accommodated by representational activities directed at improving the reputation of the team by showcasing their success $[11,14]$.

Hence, we propose that:

H2: Different stages of the project lifecycle are likely to be accompanied by distinct boundary-spanning activities.

Specifically:

H2a: The initiating stage will be characterized by a higher number of information search as opposed to representation or coordination activities

$H 2 b$ : The planning stage will be accompanied by representation and coordination activities as opposed to information search activities

H2c: The executing stage will be characterized by a higher number of coordination as opposed to representation or information search activities

H2d: The closing stage will be characterized by a higher number of representation as opposed to coordination or information search activities

\section{Research Design}

\subsection{Data Collection}

This study involves data from the $\mathrm{ESM}^{1}$ of a large, multinational Fortune 500 provider of workplace products, furnishings, and services. The Company has approximately 11,000 employees around the world and is headquartered in the U.S. with 80 locations (in 40 countries) in North and South America, Europe, Africa, Asia, Oceania, and the Middle East.

Specifically, we collected data from 169 project teams for which complete log, content, and project data was available. Within the ESM platform, any user who is a project manager can create a project and make use of a range of project management features, such as those for creating and assigning tasks, displaying events and "checkpoints" on a calendar, generating status updates, blog posts and discussions related to the project, and uploading relevant project files. Each project has a landing page with an overview of recent activity, a project calendar, and links to related posts and files. The project manager determines when a project is complete, and the site is archived. For the purpose of this study, we focused on the content of

\footnotetext{
${ }^{1}$ The company uses the Jive ESM from http://www.jivesoftware.com
} 
inter-team interactions to determine boundaryspanning activities as well as performance measures (i.e. was the project successfully completed or not) from this project management system in the ESM platform.

\subsection{Operationalization}

In an earlier article, [34] developed a machinelearning algorithm that classifies various interactions occurring in two ESM formats (blog posts and discussion posts) as one of the three boundaryspanning activities or other. Following ten-fold cross validation, the final algorithm performed with an accuracy of $86.2 \%$ as compared to human coders.

Applying the same algorithm on the current data set, $32.9 \%$ of interactions between the project teams in our data set consisted of representational activities, $24.7 \%$ of coordination activities, and $20.5 \%$ of information search activities. Furthermore, an additional $21.9 \%$ consisted of interactions that could not be classified as one of the three boundary-spanning activities. These were further broken down into workrelated $(6.8 \%)$ and social $(15.1 \%)$ posts.

As for the operationalization of the dependent variable; we relied on two performance measures that are extracted from the logs of the project management system in the Company's ESM. The first measure is a simple effectiveness measure of project success in terms of whether or not the project was completed. This indication is made by the project manager once he or she has determined that the project work is done. The second measure is an efficiency measure that reflects whether or not the project was completed on time. When a project is created within the ESM, a desired completion date is specified, allowing a rough determination of whether this goal was met, or that the project was not completed on time.

\subsection{Analysis and Hypothesis Testing}

In order to examine our first hypothesis regarding the overall effect of boundary spanning and the three boundary-spanning activities on project successusing the two abovementioned measures of success (effectiveness (completed or not) and efficiency (on time or not)), we used logistic regressions given the categorical nature of our dependent variables.

In order to map the boundary-spanning activities to the project lifecyle, we used a qualitative path analysis method developed by [30]. This involves manually mapping critical events and their anticipated dependent variables. In the case of this study, it involved mapping the time of the occurrence of a boundary-spanning activity to the timeline of the project, so as to create a path model that shows the links between certain types of activities and specific stages and transitions of the project.

Finally, in order to test our second set of hypotheses regarding the dominant boundary-spanning activities in each of the project stages, we used basic means comparisons for only the successful projects as we are interested in assessing statistical differences in the prevalence of boundary-spanning activities for each project stage.

All statistical analyses were completed in the LME4 package in $\mathrm{R}$.

\section{Findings}

\subsection{Team Boundary Spanning and Project Success}

Our findings regarding the effect of the occurrence of boundary spanning on project success show that the effectiveness of a project is significantly associated with the amount of representational activities $(\mathrm{B}=$ $.214 ; \mathrm{p}=.007)$ and the amount of information search activities $(\mathrm{B}=.185 ; \mathrm{p}=.02)$. The amount of coordination activities demonstrated borderline significance $(\mathrm{B}=.133 ; \mathrm{p}=.09)$.

Furthermore, we find that the efficiency of a project-whether it is completed on time or not-is significantly associated with the amount of representational activities $(\mathrm{B}=.153 ; \mathrm{p}=.01)$, but not by the amount of information search $(\mathrm{B}=.120 ; \mathrm{p}=$ $.270)$ and coordination activities $(\mathrm{B}=.101 ; \mathrm{p}=.423)$.

Hence, the findings show strong support for $\mathrm{Hla}$, moderate support for $\mathrm{H} 1 \mathrm{c}$ and weak support for $\mathrm{H} 1 \mathrm{~b}$, showing that representation activities occurring on ESM are the most critical with respect to project effectiveness and efficiency, whereas information search is only important for project effectiveness. Coordination appears to have no effect on project efficiency and marginal effects on project effectiveness. The summary of findings is also presented in Table 2 below.

\begin{tabular}{|l|l|l|}
\hline Hyp. & Relationship & Supported \\
\hline 1 & $\begin{array}{l}\text { Boundary Spanning } \\
\text { Success }\end{array}$ & Partially Supported \\
\hline 1a & Representation > Success & $\begin{array}{l}\text { Supported for both } \\
\text { effectiveness and } \\
\text { efficiency }\end{array}$ \\
\hline 1b & Coordination > Success & Not Supported for \\
\hline 1c & Info Search > Success & $\begin{array}{l}\text { Supported } \\
\text { Effectiveness; not for } \\
\text { Efficiency }\end{array}$ \\
\hline
\end{tabular}

Table 2. Findings for Hypothesis 1 


\subsection{Team Boundary Spanning and the Project Lifecycle: Qualitative Path Analysis}

Figure 1 provides the results of our qualitative path model of boundary-spanning activities vis-à-vis the stages of the project lifecycle by comparing successful versus unsuccessful projects.

Figure 1 shows that for projects that are successful in terms of effectiveness (completed or not), the dominant boundary-spanning activity during the initiating stage is information search; during the planning stage it is coordinating, during the executing stage it is coordinating, and during the closing stage it is representation. An additional observation about the difference between successful and unsuccessful projects, as depicted in Figure 1, is that unsuccessful projects are dominated by information search activities throughout all stages of the project lifecycle.

Indeed, representational and coordination activities are less frequently enacted and at some stages, not enacted at all.

Successful projects, on the other hand, show a steady increase in the number of representational activities over time, whereas information search activities decrease as the project progresses and coordination activities are concentrated during the middle two stages of a project's lifecycle.

\begin{tabular}{|c|c|c|c|c|c|}
\hline & Intitating & Planning & Executing & Closing & Description \\
\hline Successful Projects & & - & & & $\begin{array}{ll}= & \text { Representation } \\
= & \text { coordination } \\
\text { - } & \begin{array}{l}\text { Information } \\
\text { Search }\end{array}\end{array}$ \\
\hline Unsuccesstul Projects & & & & & 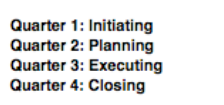 \\
\hline
\end{tabular}

Figure 1. Boundary Spanning Activities by Project Lifecycle Stage

\subsection{Team Boundary Spanning and the Project Lifecycle: Quantitative Assessment}

Finally, to further explore the results from the qualitative path analysis, we ran mean comparisons for the three boundary-spanning activities in each of the project lifecycle stages to see if certain activities are more prevalent in specific stages of the project. For this analysis, we only used The findings (see Table 3 ) reveal that for the initiating stage of a project, no significant differences exist between the three boundary-spanning activities; hence, even though information search is the most dominant activity in terms of frequency $(\mathrm{N}=83)$ compared to representation $(\mathrm{N}=39)$ and coordination $(\mathrm{N}=50)$, the differences are not significant $(\mathrm{p}=.246$ and $\mathrm{p}=.249)$. Hypothesis $2 \mathrm{a}$ is not supported, even though the raw numbers reveal that information search is more dominant during this stage.

For the second stage of the project lifecycle, the planning stage, our findings show that both representation $(\mathrm{p}=.044)$ and coordination $(\mathrm{p}=.079)$ are significantly more prevalent during a successful completion of the planning stage than information search. The difference between representation and coordination is not significant, revealing that both activities are equally prevalent during the project lifecycle. Thus, hypothesis $2 \mathrm{~b}$ is supported.

For the third stage of the project lifecycle, the executing stage, the results show that coordination occurs significantly more frequently than information search activities $(p=.062)$; however, no significant difference with representational activities was observed $(p=.408)$. Thus, coordination is the most dominant activity during the executing stage, but it is equally important to the successful completion of the third project stage as representation. Thus, hypothesis $2 \mathrm{c}$ is partially supported.

Finally, for the fourth stage of the project lifecycle, the closing stage, our results show that representational activities are most dominant during the final project stage, when compared to both coordination $(\mathrm{p}=.047)$ and information search $(\mathrm{p}=$ 
.035) activities respectively. Thus, hypothesis $2 \mathrm{~d}$ is supported.

\begin{tabular}{|l|l|l|}
\hline Hyp. & Relationship & Supported \\
\hline 2 & $\begin{array}{l}\text { Different Boundary- } \\
\text { Spanning Activities in } \\
\text { Different stages }\end{array}$ & Partially Supported \\
\hline $2 \mathrm{a}$ & $\begin{array}{l}\text { Initiating: Info Search > } \\
\text { Representation } \\
\text { Coordination }\end{array}$ & Not Supported \\
\hline $2 \mathrm{~b}$ & $\begin{array}{l}\text { Planning: Representation } \\
\text { \& Coordination > Info } \\
\text { Search }\end{array}$ & Supported \\
\hline 2c & $\begin{array}{l}\text { Executing: Coordination > }> \\
\text { Representation \& Info } \\
\text { Search }\end{array}$ & $\begin{array}{l}\text { Supported for Info } \\
\text { Search, not for } \\
\text { Representation }\end{array}$ \\
\hline 2d & $\begin{array}{l}\text { Closing: Representation > > } \\
\text { Coordination \& Info } \\
\text { Search }\end{array}$ & Supported r \\
\hline
\end{tabular}

Table 3. Findings for Hypothesis 2

\section{Discussion}

In this paper, we first tested our overall hypothesis, that is, whether boundary spanning positively affects the effectiveness and efficiency of project completion as proxies for project success. Our results showed that overall, enacting boundary-spanning activities appear more critical for the successful completion of projects (effectiveness) and less influential with respect to the on-time completion of projects (efficiency). Specifically, both representation and information search activities were significant predictors of project effectiveness and representation was a further antecedent to project efficiency. One explanation for this latter finding might be that teams that fail to engage in adequate representation fail to secure necessary resources, causing project delays. These results help to address the first research question underpinning this study, namely to validate if boundary spanning contributes to successful project completion using unobtrusive data regarding both the independent variables (i.e., boundary-spanning activities) and dependent variables (project completion and on-time completion).

Our longitudinal qualitative path analysis of boundary-spanning activities vis-à-vis the project lifecycle further revealed that different boundaryspanning activities are dominant at distinct project stages, in particular when juxtaposing successful to unsuccessful projects. Specifically, information search activities seemed most dominant during the initiating stage of projects, followed by a combination of representation and coordination during the planning stage, coordination during the executing stage, and finally representation during the closing stage of a project. These findings shed light onto our second research question, namely how boundary-spanning activities evolve throughout the project lifecycle. Our qualitative path models showed highly distinct successions of boundary-spanning activities when comparing successful to unsuccessful projects.

We further found partial statistical support for our second overall hypothesis that distinct boundaryspanning activities play a critical role at different stages. Specifically, the planning and closing stages of a project seem most critically affected by specific boundary-spanning activities (representation and coordination as well as representation respectively); whereas the initiating and executing stage seem to require a more balanced portfolio of boundaryspanning activities. These results further help to address the third and final research question underpinning this study, namely which boundaryspanning activities help to predict the successful transition from one project stage to the next for each of the four stages of the project lifecycle. Indeed, the findings offered strong support for our hypothesis that the resources required by teams differ substantially from one project stage to the next, hence, that the boundary-spanning activities-communication activities that link teams to resources critical to their success - need to be aligned to reflect these different desired resources at each stage.

\subsection{Implications for Research}

The above findings offer several contributions to the literatures on team boundary spanning and ESM.

To the literature on boundary spanning, we contribute unobtrusive insights into the link between boundary spanning and project success by relying on behavioral data as recorded in situ rather than retrospective self-reports. Whereas our findings provide support for the positive effect of representation and information search on project effectiveness; we found borderline significance for the effect of coordination, and only evidence for effects of representational activities on project efficiency. Thus, it seems that boundary spanning is more critical to the effective conclusion of projects than to their on-time completion.

More importantly, beyond validating existing findings from the boundary-spanning literature with behavioral data, we provide insights into the evolution of boundary-spanning activities over time by showing that distinct activities are relevant at different stages. It is this longitudinal perspective that also seems to provide some preliminary insight into the cause of 
project failure, which may be less related to whether or not teams conduct all three activities and more related to whether or not teams conduct the activities at the right time. Specifically, it seems that the balanced roles of representation and coordination in the planning stage, the central role of coordination activities in the executing stage, and the dominance of representational activities in the closing stage are what differentiate successful and unsuccessful projects.

The longitudinal perspective contributed in this study further helps to bridge the gap between the boundary-spanning and project management literatures, by merging the theory on boundaryspanning activities with stages of the project lifecycle, as defined in the project management literature. Doing so helps us to move beyond the high-level view offered in the extant boundary-spanning literature that focuses on how the enactment of boundary-spanning activities-regardless of the timing of their occurrence-impacts overall project success, to a more granular view of the specific boundary-spanning activities that are enacted at various stages of the project. This approach allows us to reflect on the resources that are most desired and critical during a particular project stage.

Furthermore, not only do these findings help to advance theories of boundary spanning, these results further help to advance the literature on ESM in two ways. First, this study contributes to a deeper understanding of how ESMs might impact realized workplace interactions and team effectiveness and is among the first to assess the actual impact of ESM use for team boundary-spanning activities on project success.

Second, our finding that representation and information search-in the context of ESM-are significant predictors of project success, but coordination is only borderline significant, could be further evidence that ESM technologies may not offer adequate support for team coordination [31,32]. Hence, perhaps it is not the purposive lack of coordination activities, but the inability to engage in effective coordination through ESM that causes it to be a weaker predictor of overall project success. Instead, it may well be that coordination activities are managed via other modes of communication than the ESM.

\subsection{Implications for Practice}

Beyond implications for theory, the findings of this study also offer two practical contributions. First, this study is one of the first and few empirical validations of the actual impact of ESM on team activities and performance. Despite surging investments in ESM technologies, evidence of the benefits of these technologies for the organization are largely anecdotal to date [33]. Hence, this study confirms that ESM creates opportunities for teams to engage in boundary spanning and that these activities - in particular representational and information search activities - are positively associated with the effectiveness of projects.

Second, the longitudinal perspective presented in this paper also helps to provide managers and teams insights into when certain types of boundary-spanning activities - representation, coordination, and information search - are most critical. This could help teams to allocate their time and efforts to specific boundary-spanning activities at the right time rather than trying to enact all activities simultaneously. Beyond using these findings to influence what activities should be enacted when to increase the likelihood of project success, it further sheds light onto the importance for teams to use ESM (and possibly other technologies) in the context of boundary spanning and project work.

Finally, the findings from this project regarding which boundary-spanning activities should be conducted at which stage of the project lifecycle could provide the beginning steps in the development of a diagnostic tool that can help project teams and managers keep track of their activities along a project timeline and adjust their course of action accordingly. This diagnostic tool could possibly highlight when a group is doing too much of a particular activity at a stage in which this activity may not help the group yield required resources.

\subsection{Challenges and Future Research}

There are a few challenges in the existing study that highlight important avenues for future research. First, our success metrics were constrained by the data available in the system; hence, we could only look at the effectiveness and efficiency of project completion. Although these are frequently used measures of project success; additional success metrics need to be explored in the future. Additional qualitative success measures could involve integration with social network analysis to explore outcomes such as team leadership and team influence in the network of the organization as a whole.

An additional interpretation that seems warranted by the findings from the qualitative path analysis and sparks questions for future research, is that unsuccessful projects show a dominance of information search activities at all but the first stage of the project lifecycle. Yet, successful project reveal that information search only matters during the initiating stage. This finding may be a proxy for an underlying 
phenomenon, namely the extent to which project teams encompass the requisite expertise within the team for a project to be completed. The vast amounts of information search activities by unsuccessful projects seem to suggest that perhaps the project team was not well-equipped in terms of available knowledge and expertise to handle the project. This further suggests that too many information search activities may be a sign of lack of relevant knowledge within the team. Hence, future research could explore the link between information search activities and within-team project expertise. Specifically, it is worthwhile to explore if the effect of information search activities on project success is curvilinear (specifically an inverted Ushape), which could indicate that too much information search is reflective of underlying problems within the team in terms of lack of project-specific knowledge and expertise critical to project success.

Additionally, our analysis included all projects with complete information $(\mathrm{N}=169)$ that were available in the system; however, no consideration was given to the nature of the projects and the team as well as other contingencies that may affect the relationship between boundary spanning and performance [11]. Future research should explore the extent to which the nature of the project (e.g., product development or sales) as well as other structural variables, including team size and team diversity, moderate the relationship between boundary spanning and project success.

Moreover, our study looked at all boundaryspanning activities conducted by a team without looking at the individual members of the team responsible for creating the different posts. Hence, interesting avenues for future research could employ characteristics of the individual (e.g., hierarchy; tenure) to determine if different individuals are more likely to enact different activities. A related question would be to explore if groups whose members are all or equally involved in boundary spanning are more effective than groups with a designated boundary-spanner. These future avenues for research could also explore links with areas of boundary-spanning research that focus on boundary-spanning roles $[35,36]$.

Finally, in this study we only assessed the enactment of boundary-spanning activities in the context of ESM. However, in reality, teams may use other technologies and means of communicationincluding face-to-face discussions-for boundaryspanning. Hence, boundary-spanning activities that occur outside the ESM are not currently part of our evaluation. Based on this, an additional avenue for future research would be to provide not only a longitudinal perspective, but also a multi-channel view of boundary spanning to explore if particular technologies or means of communication better support specific boundary-spanning activities. This may result in specific recommendations, not just for when to enact representation, coordination, and information search, but also how to enact each activity-i.e., which channel to use for each activity.

\section{Acknowledgement}

This material is based in part upon work supported by the National Science Foundation under Grant Number IIS-1422316. Any opinions, findings, and conclusions or recommendations expressed in this material are those of the author(s) and do not necessarily reflect the views of the National Science Foundation.

\section{References}

[1] D.G. Ancona, and D.F. Caldwell, "Bridging the boundary" Administrative science quarterly, 1992a, 37, pp. 634-665.

[2] D.G. Ancona, and D.F. Caldwell, "Demography and design: Predictors of new product team performance." Organization Science, 1992b, 3, pp. 321-341.

[3] D.G. Ancona, "Outward boundary: Strategies for team survival in an organization," Academy of Management Journal, 1990, 33, pp: 334-365.

[4] V.U. Druskat and D.C. Kayes, "The antecedents of team competence: Toward a fine-grained model of self-managing team effectiveness". Research on Managing Groups and Teams, 1999, 3: pp. 01-231.

[5] A. Edmonson, "A safe harbor: Social psychological conditions enabling boundary spanning in work teams." Research on Managing Groups and Teams, 1999, 2, pp: 179199.

[6] A. Edmonson, "Speaking up in the operating room: how team leaders promote learning in interdisciplinary action teams" Journal of Management Studies, 2003, 40, pp. 14201452.

[7] L.A. DeChurch and M.A. Marks, "Leadership in multiteam systems," Journal of Applied Psychology, 2006, 91, pp: 311-329.

[8] S. Faraj and A. Yan, "Boundary work in knowledge teams," Journal of Applied Psychology, 2009, 94, pp. 604617.

[9] F. Collopy, "Biases in retrospective self-reports of time use: an empirical study of computer users." Management Science, 1996, 42(5), pp: 758-767.

[10] W. Van Osch, M. Avital, and O. Mendelson. "Biases in usefulness assessment: the realized value of generative 
support systems." Proceedings of European Conference on Information Systems. 2011.

[11] J.A. Marrone, "Team boundary spanning: A multilevel review of past research and proposals for the future," Journal of Management, 2010, 36(4), pp. 911-940.

[12] M.L. Tushman and T.J. Scanlan. "Boundary spanning individuals: Their role in information transfer and their antecedents." Academy of management journal, 1981, 24(2), pp: 289-305.

[13] W.M. Cohen, and D.A. Levinthal, "Absorptive capacity: a new perspective on learning and innovation," Administrative science quarterly, 1990, pp. 128-152.

[14] D.G. Ancona and D. Caldwell. "Beyond boundary spanning: Managing external dependence in product development teams." The Journal of High Technology Management Research, 1990, 1(2), pp: 119-135.

[15] M.A. Marks, J.E. Mathieu, and S.J. Zaccaro, "A temporally based framework and taxonomy of team processes," Academy of Management Review, 2001, 26(3).

[16] M.H. Jarrahi, and S. Sawyer, S. "Social Technologies, Informal Knowledge Practices, and the Enterprise," Journal of Organizational Computing and Electronic Commerce, 2013, 23(1-2), pp. 110-137.

[17] M.M. Skeels, and J. Grudin, J. "When social networks cross boundaries: a case study of workplace use of Facebook and Linkedin," Proceedings of GROUP 2009. ACM Press, 2009.

[18] G. Von Krogh, "How does social software change knowledge management?" The Journal of Strategic Information Systems, 2012, 21(2), pp. 154-164.

[19] P.M. Leonardi, "Social media, knowledge sharing, and innovation: Toward a theory of communication visibility." Information systems research, 2014, 25(4), pp: 796-816.

[20] P.M. Leonardi, M., Huysman, and C. Steinfield, "Enterprise social media" Journal of Computer Mediated Communication, 2013, 19(1).

[21] J.W. Treem, and P.M. Leonardi, "Social media use in organizations: Exploring the affordances of visibility, editablity, persistance, and association," Communication Yearbook, 2012, 36.

[22] J.M. DiMicco, D.R. Millen, W. Geyer, W., and C. Dugan, "Research on the Use of Social Software in the Workplace," Computer Supported Collaborative Work. San Diego, CA, USA, 2008.

[23] J.M. DiMicco, W. Geyer, C. Dugan, B. Brownholtz, and D.R. Millen. "People Sensemaking and Relationship Building on an Enterprise Social Networking Site," Proceedings of HICSS, 2009.
[24] C. Steinfield, J.M. DiMicco, N.B. Ellison, and C. Lampe, "Bowling online: social networking and social capital within the organization," Proceedings of C\&T '09, ACM, New York, NY, USA, 2009, pp. 245-254.

[25] KN Hampton, C-J. Lee and EJ Her, "How new media affords network diversity: Direct and mediated access to social capital through participation in local social settings,"

New Media \& Society, 2011, 13(7), pp:1031-1049

[26] JH Keitzmann, K. Hermlens, IP McCarthy and BS Silvester BS, "Social media? Get serious! Understanding the functional building blocks of social media. Business Horizons, 2011, 54(3), pp :241-251.

[27] A.B. Hargadon, "Firms as knowledge brokers" California Management Review, 1998, 40, pp. 209-227.

[28] S.A. Mohrman, S.G. Cohen, and A.M. Mohrman. Designing team-based organizations: New forms for knowledge work. San Francisco: Jossey-Bass, 1995.

[29] PMBOK Guide, 4th Edition, Copyright to the Project Management Institute (PMI).

[30] W Van Osch, R Bohnsack and M Avital, "From Green IT to Sustainable Value: The Path-Dependent Construction of Sustainable Innovation." Academy of Management Proceedings. Vol. 2010. No. 1. Academy of Management, 2010.

[31] W. Van Osch and C. Steinfield. "Boundary Spanning through Enterprise Social Software: An External Stakeholder Perspective." Proceedings of the International Conference on Information Systems, 2013.

[32] W. Van Osch and C. Steinfield, "Intra-Organizational Boundary-Spanning: Strategic Implications for the Implementation and Use of Enterprise Social Media". Journal of Information Technology, 2016.

[33] W. Van Osch. "The Business Side of Social Media," International Innovation, 2015, 95, pp: 27-29.

[34] W. Van Osch, C. Steinfield, and Y. Zhao. "Team Boundary Spanning through Enterprise Social Media: Exploring the Effects of Group-Level Diversity Using a Data Science Approach," In 2016 49th Hawaii International Conference on System Sciences (HICSS) (pp. 2176-2185). IEEE.

[35] D. Katz and R.L. Kahn, The Social Psychology of organizations, New York: John Wiley.

[36] M.L. Tushman, "Special boundary roles in the innovation process," Administrative Science Quarterly, 1977, 22 pp: 587-605. 